\title{
Training experience with community health agents: Focus on prevention and identification of stroke
}

\author{
Ludimila Santos Muniz ${ }^{* 1}$, Claudenice Ferreira dos Santos ${ }^{2,3}$, Mariana de Almeida Moraes ${ }^{4}$, Elieusa e Silva Sampaio ${ }^{4}$, \\ Cláudia Geovana da Silva Pires ${ }^{4}$, Fernanda Carneiro Mussi ${ }^{4}$ \\ ${ }^{1}$ Hospital Geral Roberto Santos, Brazil \\ ${ }^{2}$ Jorge Amado University, Brazil \\ ${ }^{3}$ University of the State of Bahia, Brazil \\ ${ }^{4}$ School of Nursing, Federal University of Bahia, Salvador, Bahia, Brazil
}

Received: January 17, 2021

DOI: $10.5430 /$ jnep.v11n7p63
Accepted: March 15, 2021

Online Published: March 25, 2021

\begin{abstract}
Objective: To describe the experience of nurses in the process of training community health workers for the prevention and early identification of risk factors and warning signs of Stroke and for community actions before the cerebrovascular event.

Methods: This is a report of an educational intervention with 1,302 community health workers from 12 Health Districts of Salvador. Thirty-four four-hour meetings were developed. The strategies and resources used included reflection dynamics on the impact of Stroke, exhibition classes, use of videos and informative pamphlets.

Results: The educational activities allowed reflections on the repercussions of Stroke on the daily life of victims and their families, as well as on access to health services and the role of community health workers in those contexts.

Conclusions: The experience contributed to the qualification of the work of the community health workers in preventive actions for identification and early intervention in the Stroke.
\end{abstract}

Key Words: Stroke, Community health workers, Health education

\section{INTRODUCTION}

Stroke, whose incidence is of 108 cases per 100,000 inhabitants in Brazil ${ }^{[1]}$ has high morbidity and mortality rates. It generates disabilities that reduce the quality of life of individuals, disorganizes the family structure and burdens the health system due to the high cost of care and treatment, at all care levels.

In recent decades, the use of thrombolytic reperfusion therapy in Ischemic Stroke and treatment in Stroke units is among the most effective measures to reduce mortality and functional disability. ${ }^{[2]}$ The success of thrombolytic treatment depends on the rapid identification of warning signs by the population, the call or immediate referral to the emergency service, prioritization of pre- and intra-hospital transportation, adequate communication among health professionals, early access to neuroimaging and rapid diagnosis and treatment, through pre-established protocols. ${ }^{[2]}$ The efficacy of treatment is directly related to the time of onset of the first symptoms and the administration of the drug in a window of four hours and thirty minutes, diligent in reducing severe sequelae of Stroke in the hyperacute phase.

Although Stroke has a high prevalence, being the leading

*Correspondence: Ludimila Santos Muniz; Email: ludimuniz@ hotmail.com; Address: Hospital Geral Roberto Santos, Brazil. 
cause of death in Brazil and having a care program for patients with Stroke, at all care levels, the aim is to achieve the recognition of the event by the population, where there is still a great lack of information on the prevention, identification and treatment of the event, by both the population and health professionals. ${ }^{[3]}$

In 2012, managers of a large hospital in the state of Bahia implemented the first Stroke unit, with 14 beds, becoming a reference center for the hyperacute treatment of the disease. Nurses in this unit observed that users and family members delayed the search for care due to unawareness of the signs and symptoms and the existing treatment. This delay reduces the chances of secondary prevention of sequelae in people at risk for the occurrence of the disease. ${ }^{[4]}$

In view of the above, the nurses reflected on what to do to minimize the lack of information in communities in the city of Salvador. In 1997, with the purpose of reorganizing public health and the Brazilian care model, the Family Health Strategy was created, comprising an important healthcare program. ${ }^{[5]}$ Knowing that the monitoring of the population by the Family Health Strategy is a tool for health care, which seeks to promote the quality of life of the Brazilian population and intervene in the factors that put health at risk ${ }^{[5]}$ the importance of working with Community Health Workers was emphasized. The Community Health Workers develop an important role in the Family Health Strategy. They closely monitor families through home visits and one of their functions is to guide them regarding the use of available health services and to develop, permanently, educational actions that aim at health promotion, disease prevention and monitoring health problems. ${ }^{[5]}$ Those agents can assist families in recognizing early warning signs of Stroke and identifying the appropriate service to be sought, as well as offering support after the event by monitoring the functional needs of the contribute victim and guiding the prevention of new events. The community health workers perform the function of social mobilizers, mediating and building knowledge in the exercise of professional/citizen practice, in direct contact with the community. ${ }^{[6]}$

Thus, the nurses understood the training of those agents, who are fundamental interlocutors between health services and the population, as being a strategy to achieve the reduction of sequelae and death from Stroke, based on the premise that Primary Health Care has a strategic character and it is the branch of care with the greatest potential to identify the health needs of the population. Thus, Primary Health Care together with the Hospital Network add up in capacity and efforts to promote prevention, produce care and prevent sequelae and deaths from Stroke.
Based on the above, this study aimed to describe the experience of nurses in the process of training community health workers for the prevention and early identification of risk factors and warning signs of Stroke and for community actions before the cerebrovascular event.

\section{METHOD}

\subsection{Design}

This is an experience report on health education activities developed by three nurses with the community health workers who worked in 12 Health Districts of Salvador/BA.

\subsection{Sample}

Access was to a population of 1,316 community health workers. All of these were invited to take part in the training and 1,302 accepted an participated in the Educational interventions from October 2016 to October 2018.

\subsection{Tools and procedures}

The health education activities were governed by the Brazilian National Policy of Permanent Education in Health. ${ }^{[6]}$ This policy guides the education actions in compliance with the principles and guidelines of the Brazilian Unified Health System (SUS). The guidelines of the Ministry of Health's Manual of Routines for Attention to Strokes (2013) and the guidelines for Acute Ischemic Stroke Treatment of the Brazilian Stroke Society and The Scientific Department in Cerebrovascular Diseases of the Brazilian Academy of Neurology and Collaborators were used.

The insertion of community health agents was sought and the establishment of a dialogic relation with them, under the perspective of identifying their knowledge in relation to the care and treatment of individuals with strokes, what they would like to know about the matter and awareness of their experience in caring for the family and difficulties faced.

To ensure the training of this number of agents, 34 meetings were held. In each four-hour meeting, up to 45 community health workers participated. Each group of 45 community health workers attended one or two meetings. In 2018, two interventions were carried out for the absentee, aiming to reach $99 \%$ of the total Community health workers, since about $1 \%$ were not at work being on leave, among other reasons.

In the planning phase of the educational activities, a partnership was established with the techniques of the Thematic Field Chronic Diseases/Coordination of Primary Health Care/Health Care Directorate/Municipal Health Department of Salvador. The Municipal Health Department exempted the community health workers for participation in the interventions and provide space reservation and audiovisual 
resources for the training, which took place at schools, community centers, health units, university auditoriums and the said hospital. The three nurses of the Stroke unit were responsible for the preparation, implementation and evaluation of educational activities, together with professionals from the city hall who helped manage them.

The strategies and resources used were dynamics of reflection on the impact of Stroke on the lives of victims, exhibition classes on the subject, use of videos and informative pamphlets. For the execution of the educational activities, lesson plans were elaborated and informative materials were selected to deliver to the Community health workers, such as the Pamphlet on Stroke Occurrence and its Relationship with Risk Factors (Source: Rede Brasil AVC) ${ }^{[7]}$ and the Mnemonic on warning signs for Stroke (Source: Rede Brasil AVC). ${ }^{[7]}$ Videos were used during health education activities to discuss Stroke outcomes of care.

A group dynamic to promote reflections on the impact of Stroke on the daily life of victims and family members was also used in training. In this, seven common problems were listed after Stroke such as incontinence pads, difficulty in speaking, swallowing, writing and having sex, double and blurred vision and wheelchair use. Those deficits/problems were drawn among the community health workers and, later, they were asked to talk about what would change in their lives if, suddenly, they were affected by the disease and had such deficits.

In the educational interventions, the approach included the definition of Stroke, the magnitude of the problem, epidemiological data, signs and symptoms, warning signs, risk factors, primary and secondary prevention, rapid identification and activation of the emergency service, thrombolytic treatment, presentation to specialized services in Salvador/BA, opening of space for dialogue, discussion and oral evaluation of the intervention.

\subsection{Analysis of results}

At each meeting, the activities were commented and evaluated by the community health workers through free speech, registered by one of the nurses in a proper form. In the analysis of the testimonies, all the themes reported by the community health agents were extracted with the respective descriptions.

\subsection{Ethical aspects}

All participants were informed of the study and consented to participate in the process of training community health workers. They verbally declared their interest in taking part and were assured that they could decline at any time, should they judge it necessary, without prejudice.

Published by Sciedu Press

\section{Results}

During the group dynamics, the community health workers expressed emotional statements, verbalized fear of being victims of Stroke and shared experiences in the community with people with Stroke and their families, being a very rich moment of exchange of experiences among the actors involved in the dynamics.

The vast majority said they did not know about the disease and the possibilities of treatment before the intervention. They mentioned that many educational programs and campaigns are made in the Family Health Strategy, but that Stroke is rarely a matter of community care. They portrayed the difficult reality of hypertensive people who have suffered Stroke and face difficulty in accessing treatment in Emergency Care Units. They considered the training relevant because it was a space for dialogue, to learn about prevention and early identification of Stroke and to know the Stroke care network, which they evaluated as essential to optimize the referral of people in a frame suggestive of the event to the reference health services aimed at early treatment.

Most community health workers recognized the importance of their work and felt involved in helping prevent, recognize and act against Stroke in communities. They considered the experience fundamental to the qualification of care and treatment of people with Stroke. However, some reported difficulties to be multipliers of information due to overload in the work process. Others reported experiencing unhealthy working conditions, without due recognition by management bodies. The community health workers also expressed criticism of hospital care and the delay in the arrival of the Mobile Emergency Prehospital Service to help the victims.

In recognition of the relevance of this educational intervention, we received the Good Practices Award of the State Government Worker 2017, with the 3rd place.

\section{Discussion}

Some authors ${ }^{[6]}$ consider it necessary to train and qualify the community health workers for the transformation and qualification of health practices, improvement of the quality of services and the continuous work of community awareness for health promotion, prevention and control of injuries. With the training, we share experiences and knowledge about the prevention and treatment of Stroke, contributing to the community health workers in Primary Care in Salvador to be multipliers of knowledge to people at risk of suffering this event. $^{[4]}$

Since the intervention, there has been a $40 \%$ increase in the number of thrombolysis in the hospital in 2017, strengthening the articulation with the community, primary care network 
and hospital care for Stroke victims. This reveals the importance of integrated actions in health and health education, as well as reinforcing the important role of community health workers of communicating with people and establishing a bond between the community and the health system. ${ }^{[9]}$ Another study disclosed that the lack of knowledge by the health professionals was an obstacle for assuring the quality of care for individuals who suffered a stroke. ${ }^{[10]}$

The community health workers considered the training important to learn about the subject and contribute to disseminate knowledge among families and people at risk. They considered themselves capable of identifying signs and symptoms, risk situations and guiding families to recognize the event and trigger medical help. They highlighted that they can refer the cases and situations identified to the team. Actions that bring benefits to the assisted families. ${ }^{[9]}$

The experience revealed that the community health workers know the reality where they work, understand the values of the community and the linguistic field where they are located, and can open paths in the process of health intervention. ${ }^{[8]}$ Thus, they have the potential to multiply health information and embrace service users and family members. The Municipal Health Department of Salvador techniques highlighted the importance of health education for Stroke due to the high worldwide prevalence, ${ }^{[2]}$ that the multiplication of information by the community health workers of Salvador contributes to the early identification of events by the population and, consequently, to the prevention of more serious sequelae. The strategies and resources used in the activities illuminated the content approach in a dynamic, playful, attractive and participative way, contributing to the intended reflections and learning, suggesting their use. The community health workers report that the theme Stroke was rarely addressed in educational programs and campaigns made in the Family Health Strategy, which reveals the need for investments in this field of training to act competently and skillfully in the communities. Some authors emphasize that knowledge and professional integrity in relation to the disease could be improved through various actions such as training, public campaigns, interaction with family members having suffered a stroke and professional experience, corroborating with our findings. ${ }^{[11]}$
The difficulties reported for becoming multipliers of learning about Stroke were informed as overload in the work process, thus unhealthy working conditions, deserve a sensitive listening by health managers. Increased workload and wellbeing have a cause-effect relation related to excessive overtime, extensive tenures in the work environment are stressors associated to the health professionals. ${ }^{[12]}$ Health administrators and community agents need to share expectations, limits and possibilities to reach alternatives that minimize the barriers to the work of community health workers and that express the recognition of the value of their work.

The community health workers expressed criticism of hospital care and the delay of Mobile Emergency Prehospital Service, evidencing the lack of coverage of care to the vulnerable population, which generates a feeling of impotence. The community health workers should be partners in the evaluation of public health services, translating barriers and limits of access to services by the population, as well as community partners empowering them to defend their health rights. It is worth noting that the delay in the attention to individuals suffering a Stroke is associated to a poor post-event prognosis, ${ }^{[13]}$ enhancing the pertinence of the criticisms of the Community Health Agents and the need for improved support from the health system. ${ }^{[13]}$

\section{Conclusion/Final CONSIDERATions}

The experience contributed to the qualification of the work of the community health workers in preventive actions, identification and early intervention of Stroke within the community. The transversality of Primary Care in health care networks and the role of community health workers in the dialogue between the population and services highlight them as important in reducing Stroke morbidity and mortality. The permanent education of community health workers contributes to the early search for services, monitoring and support to victims and family members after the event, reducing negative outcomes. Intervention studies with robust methodologies and analyses will better demonstrate the effectiveness of the educational activities carried out.

\section{CONFlicts OF INTEREST Disclosure}

The authors declare that there is no conflict of interest.

\section{REFERENCES}

[1] Botelho TS, Neto CDM, Araújo FLCA, et al. Epidemiologia do acidente vascular cerebral no Brasil. Temas em Saúde, João Pessoa. 2016; 16(2): 2447-2131.

[2] Brasil, Ministério da Saúde. Portaria ${ }^{\circ} 664$ de 12 de abril de 2012. Aprova o Protocolo Clínico e Diretrizes Terapêuticas- Trombólise no
Acidente vascular cerebral Isquêmico Agudo. Brasília-DF, Publicado no DOU de. 2012.

[3] Filho JO, Martins SCO, Neto OMP, et al. Guidelines for acute ischemic Stroke treatment: part I. Arq. Neuro-Psiquiatr. São Paulo. 2012; 70(8): 621-629. PMid:22899035 https://doi.org/10.1 590/S0004-282X2012000800012 
[4] Maniva SJCFM, Carvalho ZMF, Gomes RKG, et al. Educational technologies for health education on Stroke: an integrative review. Rev. Bras. Enferm. 2018; 71(4): 1724-1731. PMid:30088646 https://doi.org/10.1590/0034-7167-2017-0041

[5] Brasil. Portaria n ${ }^{\circ} 2436$ de 21 de setembro de 2017. Política Nacional de Atenção Básica. Available from: http://bvsms. saude.gov .

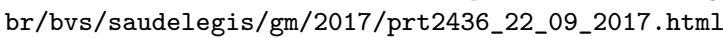

[6] Rocha NHN, Bevilacqua PD, Barletto M. Metodologias participativas e educação permanente na formação de agentes comunitários/as de saúde. Trabalho, Educação e Saúde. 2015; 13(3): 597-615. https://doi.org/10.1590/1981-7746-sip00056

[7] Rede Brasil AVC. 2018. Available from: http://www.redebras ilavc.org.br/

[8] Godoi BB, Madeira ALF, Alfradique BM, et al. Capacitação de agentes comunitários de saúde no município de Diamantina/MG. Rev. Ciênc. Ext. 2018; 14(1): 54-69.

[9] Cardoso FA, Cordeiro VR, Lima DB, et al. Capacitação de agentes comunitários de saúde: experiência de ensino e prática com alunos de Enfermagem. Rev Bras Enferm, Brasília. 2011 set-out; 64(5): 96873. PMid:22460503 https://doi.org/10.1590/S0034-71672 011000500026

[10] Mandizvidza V, London L, Bryer A. Shortfall in stroke care: A study of ischemic stroke care practices in a South African metropole. South African Medical Journal. 2021; 111(3): 215-9. https ://doi.org/ 10.7196/SAMJ . 2021.v111i3.15104

[11] Bridgwood BM, et al. Knowledge of peripheral artery disease: What do the public, healthcare practitioners, and trainees know? Vascular Medicine. 2020; 25(3): 263-73. PMid:32000617 https : //doi.org/10.1177/1358863X19893003

[12] Siebenher K, Battergay E, Hammig O. Temporal work stressors and satisfaction with work, life and health among health professionals in Switzerland. Swiss Medição Weekly. 2020; 150: w20175. PMid:32083703 https://doi.org/10.4414/smw . 2020.20175

[13] Amy YX, et al. Population-based study of home-time by stroke type and correlation with modified Rankin score. Neurology. 2017; 89(19): 1970-76. PMid:29021355 https://doi.org/10.1212/ WNL. 0000000000004631 